\title{
Unusual experiences and their association with metacognition: investigating ASMR and Tulpamancy
}

\section{Emma Palmer-Cooper, Nicola McGuire \& Abigail Wright}

To cite this article: Emma Palmer-Cooper, Nicola McGuire \& Abigail Wright (2021): Unusual experiences and their association with metacognition: investigating ASMR and Tulpamancy, Cognitive Neuropsychiatry, DOI: 10.1080/13546805.2021.1999798

To link to this article: https://doi.org/10.1080/13546805.2021.1999798
(C) 2021 The Author(s). Published by Informa UK Limited, trading as Taylor \& Francis Group

\section{5}

View supplementary material $๘$

\section{册Published online: 08 Nov 2021.}

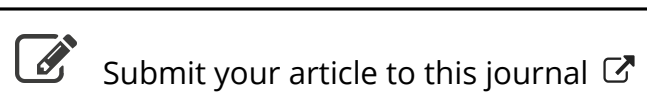

\footnotetext{
Џll Article views: 1544
}

Q View related articles $\sqsubset$

View Crossmark data ¿ 


\title{
Unusual experiences and their association with metacognition: investigating ASMR and Tulpamancy
}

\author{
Emma Palmer-Cooper (1D) ${ }^{\mathrm{a}}$, Nicola McGuire $\mathbb{D}^{\mathrm{b}}$ and Abigail Wright ${ }^{\mathrm{c}, \mathrm{d}}$ \\ ${ }^{a}$ Centre for Innovation in Mental Health, School of Psychology, University of Southampton, Hampshire, UK; \\ ${ }^{\mathrm{b}}$ Institute of Health and Wellbeing, University of Glasgow, Glasgow, UK; 'Center of Excellence for \\ Psychosocial and Systemic Research, Department of Psychiatry, Massachusetts General Hospital, Boston, \\ USA; ${ }^{\mathrm{d}}$ Harvard Medical School, Boston, USA
}

\begin{abstract}
Background: Unusual experiences in Tulpamancer and Autonomous Sensory Meridian Response (ASMR) communities are generally positive and sought after, unlike hallucinations and delusions in clinical populations. Metacognition, the ability to reflect on self-referential experiences, may aid sense-making around unusual experiences, reducing distress. This study investigated group differences in hallucination-proneness, delusion-proneness, and metacognition in these communities compared to controls, and whether metacognition predicted unusual experiences.

Methods: 243 participants reporting ASMR, Tulpamancy, or neither, with no history of psychosis, took part in an online observational study. Participants completed the Beck Cognitive Insight Scale, Metacognitions Questionnaire-30, and Brief Core Schema Scales to capture metacognition. A Tulpamancer+ (reporting ASMR) group was identified and included in analyses. ANCOVAs highlighted group differences in hallucination-proneness, with Tulpamancer+ scoring higher, and metacognitive beliefs, with Tulpamancers reporting lower metacognitive belief endorsement. There were no group differences in delusion-proneness, selfreflection, or self-schemas. Stepwise regression demonstrated metacognition does influence unusual experiences in the nonclinical population, and this influence varies across groups.

Conclusions: In non-clinical populations, unusual sensory experiences are not associated with increased metacognitive beliefs, but having multiple unusual experiences is associated with higher hallucination-proneness. Results suggest improving metacognition in clinical groups may help reduce distress related to unusual sensory experiences.
\end{abstract}

\section{ARTICLE HISTORY}

Received 3 March 2021

Accepted 26 October 2021

\section{KEYWORDS}

Metacognitive beliefs; selfschema; hallucinations; delusion-proneness; selfreflection

CONTACT Emma Palmer-Cooper e.c.palmer-cooper@soton.ac.uk E Centre for Innovation in Mental Health, University of Southampton, Shackleton Building (44), Highfield Campus, Hampshire S017 1BJ

(4) Supplemental data for this article can be accessed https://doi.org/10.1080/13546805.2021.1999798. 


\section{Introduction}

Hallucinations, or unusual sensory experiences, are recognised as perceiving sensory inputs in the absence of an objectively identifiable stimulus. Hallucinations are characteristic of psychosis and are experienced in this context as threatening or distressing (Corlett et al., 2019). Hallucinations are also common in non-clinical populations, with between $7.2-53 \%$ of general population participants reporting such experiences (De Boer et al., 2019; Linscott \& Van Os, 2013; Pechey \& Halligan, 2012). Distress and functional impairment caused by hallucinations are two of the key differences between the experience of clinical and non-clinical populations (Waters \& Fernyhough, 2017).

\section{Non-clinical hallucination-like experiences}

Several communities have emerged for individuals who regularly experience positive and sought-after unusual sensations. Tulpamancers create the concept of a Tulpa, an imagined, invisible entity who gains sentience through the use of Tibetan Buddhist meditative practises (Mikles \& Laycock, 2015). Tulpamancers associate tulpas with positive impacts on mental health and overall life (Isler, 2017). There has been a growth in online communities on social media who share experiences as well as support and guidance for developing tulpas.

Autonomous Sensory Meridian Response (ASMR) is a "sensory phenomenon" where individuals experience a physical tingling sensation in their scalp and neck during exposure to specific audio or visual stimuli, or "triggers". ASMR triggers differ between individuals, however, research indicates that there are a number of "types" of triggers, with stimuli involving whispering, personal attention, crisp sounds and slow, and careful movements being the most commonly reported to induce ASMR (Barratt \& Davis, 2015; Roberts et al., 2021). ASMR can be experienced "offline", in everyday life, but there has been a growth in dissemination and consumption of videos that can trigger ASMR online (Barratt \& Davis, 2015). Further, many people have an optimal "trigger load", or combination of triggers in one video, with research finding the most commonly preferred load is two triggers in one video (such as whispering and personal attention) (Barratt et al., 2017). Although sensory input is related to this experience, it is not congruent with the physical output and evidence suggests that ASMR has been linked to synaesthesia; a sensory phenomenon in which one sensory pathway (e.g. taste) leads to an experience of a second sensory pathway (e.g. smell), suggesting ASMR is touchemotion synaesthesia (Poerio, 2016). ASMR is often accompanied by a feeling of calmness and positive affect (Poerio et al., 2018) and is suggested to be a pleasant experience that is associated with absorption (McErlean \& Osborne-Ford, 2020), the ability to focus one's attention on one entity or experience, but is not associated with trait mindfulness (Roberts et al., 2021), nor cultivated through practice. The differences in the appraisal of sensory experiences between the ASMR and Tulpamancer communities and clinical populations are perhaps then an important contributor to experience-related distress. 


\section{Metacognition}

Metacognition is the capacity to be aware of oneself, including one's goals, thoughts, feelings, behaviours, and knowledge (Lysaker et al., 2013, 2019). Individuals with a psychotic disorder who experience hallucinations have greater difficulties or deficits in accurately reflecting on and understanding their thoughts and mental experiences (Hill et al., 2012; Trauelsen et al., 2016; Beck et al., 2004). Deficits in metacognition may contribute to both the production and maintenance of distressing hallucinations (Wells, 2007), and result in the misinterpretation of specific experiences as distressing or threatening. Deficits in metacognition may impair reappraising these experiences as non-threatening, thus maintaining these experiences. Research has indicated that the relationship between metacognition and hallucination-proneness is stronger in non-clinical than in clinical populations (Varese \& Bentall, 2011).

When metacognition functions appropriately, awareness of oneself and reflection on one's experiences may increase, reducing distress associated with these experiences. In the general population, more sub-clinical levels of schizotypal traits were associated with higher metacognitive awareness, suggesting individuals in the general population may be aware of unusual experiences but do not experience distress from these experiences (Palmer-Cooper et al., 2020). With this in mind, the suggestion that those experiencing ASMR or identifying as Tulpamancers may be able to better reflect on their experiences is an important consideration, but metacognitive awareness in these groups has not been empirically studied.

Evidence has also shown metacognitive beliefs about the usefulness of paranoia and unusual thoughts can maintain delusion-proneness in clinical groups (Morrison et al., 2011). Further, lower self-reflectiveness (Carse \& Langdon, 2013) and higher overconfidence in beliefs is associated with higher levels of delusion-proneness (Ekinci et al., 2012; Kimhy et al., 2014). Delusions are fixed false beliefs which occur outside of the cultural norm (Garety \& Freeman, 1999) and occur frequently in the general population (Freeman et al., 2010). It, therefore, seems pertinent to investigate delusion-proneness in these non-clinical groups with unusual sensory experiences.

Where metacognitive awareness can be considered self-referential processing (e.g. "I am constantly aware of my thinking"), schemas concerning oneself can be considered self-referential content (e.g. "I am good" or "I am bad"). Studies have reported an association between negative schemas towards self and others with delusion-proneness, specifically paranoia (Fowler et al., 2012; Gracie et al., 2007; Smith et al., 2006), and beliefs about hallucinations (Thomas et al., 2015) or content of hallucinations (Scott et al., 2021). There is also a noted association between negative self-schemas and persecutory delusions in the general population (Kesting \& Lincoln, 2013). However, no studies have examined the relationship between schemas and hallucinations or delusion-proneness in our groups of interest.

This research study aimed to compare self-reported metacognitive beliefs (beliefs about one's thoughts) and awareness (awareness of thought processes, e.g. "I am constantly aware of my thinking" MCQ-30), and self-reflection (ability to consider other people's thoughts), e.g. "Even though I feel strongly that I am right, I 
could be wrong" BCIS), as well as schemas (beliefs about the self, e.g. "I am good" BCSS) in three non-clinical populations: those experiencing ASMR, Tulpamancers, and those with neither unusual sensory experience, to attempt to explain the relationship between hallucination-proneness and metacognition. Additionally, the relationship between metacognition and delusions in these groups will be investigated.

\section{Hypothesis}

H1: Individuals who experience ASMR or who identify as Tulpamancers will have higher hallucination-proneness (MUSEQ scores) than individuals who do not have these experiences.

H2: Individuals who experience ASMR or who identify as Tulpamancers will have higher delusion-proneness (PDI scores) than individuals who do not have these experiences.

H3: Individuals who experience ASMR or who identify as Tulpamancers will demonstrate better metacognition (higher BCIS self-reflectiveness scores; lower MCQ-30 scores) and more positive self-schemas (high positive and low negative self BCSS) than individuals who do not have these experiences.

H4: Metacognition scores (BCIS self-reflectiveness scale; MCQ-30) and self-schemas (BCSS) will predict hallucination-proneness (MUSEQ scores) and delusion-proneness (PDI scores) in these non-clinical groups.

We will also explore which metacognitive variable is the most predictive of hallucination-proneness and delusion-proneness across the groups using step-wise regression models.

\section{Methods}

\section{Participants}

Three groups of participants were recruited for this study:

(1) Participants who experience Autonomous Sensory Meridian Response (ASMR);

(2) Participants from Tulpamancy communities who have a Tulpa;

(3) Participants who do not belong to either community.

Groups 1 and 2 were recruited through targeted online, opportunity sampling methods, for example through social media and Reddit.com in dedicated online communities and groups for individuals who experience ASMR (Reddit, n.d.a) or Tulpamancy (Reddit, n.d.b). Group 3 was recruited using online opportunity sampling methods via social media advertising, and University of Southampton student populations through the School of Psychology research participation scheme. All participants had to be 18 years old or above and have no personal or direct relative with psychotic illness [participants were asked (1) "Have you ever been diagnosed with a psychotic disorder?" and (2) "Do you have any immediate family members diagnosed with a psychotic disorder?". If they responded, "yes", they would be excluded from the study and analysis]. UoS Psychology Students received three research participation credits. No monetary compensation was received by any participant. 


\section{General procedure}

\section{Public engagement}

Prior to designing the study, the first author (EPC) approached the ASMR and Tulpamancer communities on "Reddit" (a social news aggregation, web content rating, and discussion website; (Reddit, n.d.a, n.d.b) to enquire about inviting members to take part in academic research to understand their experiences. The feedback was positive; people endorsed such research and were interested in understanding their experiences. Reddit was also used as a recruitment tool which was an effective avenue of recruitment and enabled the research team to openly respond to questions from (potential) participants.

\section{Ethical approval}

Ethical approval was obtained through The University of Southampton (ERGO Ethics Ref: 53060). Consent was sought online using a tick box, where participants indicated they read the information sheet and agree to take part. Participants were debriefed at the end of the questionnaires.

\section{Design}

This was a cross-sectional online observational study, with five questionnaires assessing metacognition (cognitive insight, metacognitive beliefs) self-schemas, and unusual experiences (hallucination- and delusion-proneness) in three groups of individuals: participants who report experiencing ASMR, participants who identify as Tulpamancers, and participants who report not belonging to these communities.

\section{Measures}

See Supplementary Methods section for information on Cronbach's Alpha for each measure by group.

\section{Self-reported ASMR/Tulpamancy}

Participants were asked "Have you ever experienced Autonomous Sensory Meridian Response, known as ASMR?" and "Have you ever experienced Tulpamancy, or had a Tulpa?" and could respond with "Yes/No/Unsure". If participants reported "unsure" to these experiences, we coded this as not experiencing these. No definition of these experiences were provided.

\section{Unusual experiences}

The Multimodal Unusual Sensory Experiences Questionnaire (MUSEQ) (Mitchell et al., 2017 ) is a 43-item scale measuring anomalous sensory experiences with 6 subscales: auditory, visual, smell, taste, bodily sensations, and sensed presence. Participants are asked to respond to the statements on a 5-point Likert scale from never (0) to frequently (4). Scores are totalled for each sensory modality. MUSEQ total score is obtained by summing all the subscale scores (0-172). Both the full scale and subscales have been demonstrated as possessing good reliability, internal consistency, discriminant validity 
between clinical and non-clinical groups, and construct validity with other anomalous experience scales (Mitchell et al., 2017). The internal consistency was $\alpha=0.95$ in this study.

The Peters Delusion Inventory (PDI) is a 21-item self-report questionnaire designed to assess delusion-proneness in the general population (Peters et al., 2004). Participants answer "yes" or "no" to 21 statements. If they answer "yes", then they are asked to rate from 1 to 5 the degree of (1) conviction, (2) preoccupation, and (3) distress of the endorsed experience on a Likert scale. A total score is devised by summing the number endorsed, conviction, preoccupation, and distress. This revised version of the PDI, the PDI-21, has demonstrated internal consistency, test-retest reliability, and validity (Peters et al., 2004). It has been shown to be appropriate for use in clinical and non-clinical groups (Balzan et al., 2016; Carse \& Langdon, 2013), including University students (Fonseca-Pedrero et al., 2012). The internal consistency was $\alpha=0.73$ in this study.

\section{Metacognition}

Beck Cognitive Insight Scale (BCIS) is a self-report questionnaire which has 15 statements rated from (0) "Do not agree at all" to (3)"agree completely" (Beck et al., 2004). The items are divided into 9-item self-reflectiveness (ability to consider the possibility that one's belief could be false; scores range 0-27) and 6-item self-certainty (overconfidence in the accuracy of one's current beliefs; scores range 0-18). A composite score is calculated by subtracting the self-certainty score from the self-reflectiveness score. Higher scores on composite and self-reflectiveness and a lower score on self-certainty reflect better metacognitive awareness. Self-reflectiveness has been linked to metacognitive monitoring (Gilleen et al., 2016; Wright et al., 2019), and cognitive biases have been assessed using the self-certainty subscale of BCIS which captures overconfidence in beliefs and may be less relevant to metacognition (Gilleen et al., 2016). The internal consistency for the self-reflectiveness subscale was $\alpha=0.65$ in this study, and $\alpha=0.57$ for the self-certainty subscale in this study.

Metacognitions Questionnaire-30 (MCQ-30; (Wells \& Cartwright-Hatton, 2004) is a 30 -item self-report questionnaire measuring individual differences in metacognitive beliefs, judgements, and monitoring tendencies on a 4-point rating scale from (1) do not agree to (4) agree very much. The questions are based on the metacognitive model of psychological disorders (Wells \& Matthews, 1994, 1996) and generally centre on the degree to which a desire to monitor and control cognitive processes is endorsed. The MCQ-30 has 5 factors: cognitive confidence (confidence in one's cognition and memory), positive beliefs about worry, cognitive self-consciousness (the tendency to focus attention on thought processes), negative beliefs about uncontrollability of thoughts and danger, and beliefs about need to control thoughts. MCQ-30 has good psychometrics: good internal consistency, validity, and test-retest reliability (Wells \& Cartwright-Hatton, 2004), and is appropriate for those with psychosis, high clinical risk, and non-clinical control participants (Austin et al., 2015; Bright et al., 2018; Jones \& Fernyhough, 2006). The internal consistency for MCQ-30 was $\alpha=0.89$ in this study.

Brief Core Schema Scales (BCSS; (Fowler et al., 2006) is a 24-item self-report questionnaire that assesses schemata concerning self and others on a 5-point rating scale (0) believe it slightly to (4) believe it totally). This scale has four dimensions of self-other 
evaluation: negative-self, positive-self, negative-others, positive-others. Scores are totalled for each of the four dimensions (score 0-24 each). This measure has good psychometric properties, including internal consistency, stability of factors, validity, and is appropriate for those with psychosis, high clinical risk, and non-clinical control participants (Addington \& Tran, 2009; Fowler et al., 2006; Smith et al., 2006). The internal consistency for BCSS positive self was $\alpha=0.82$, negative self was $\alpha=0.53$, positive other was $\alpha=0.90$, and negative other was $\alpha=0.88$ in this study.

\section{Statistical analyses}

Data was within normal limits, except PDI total showed a negative skew. We used a square root transformation. Missing data was very minimal and could acceptably be ignored by excluding those with missing data. First, analyses included obtaining descriptive statistics for each of the groups [controls, ASMR, Tulpamancers, and Tulpamancers+ (reporting ASMR)] and ANCOVAs to compare differences between the groups on psychotic experiences (MUSEQ and PDI) and metacognition (BCIS-SR, MCQ-30 total and subscales, BCSS positive self, and BCSS negative self), while controlling for age, gender, and ethnicity as these were significantly different between the groups. After this, we conducted correlations to assess associations (and covariates) between psychotic experiences and metacognition. We applied a Bonferroni-corrected $P$-value $(P<.05$ divided by number of correlations, 45 correlations $/ .05=.0011)$ for the correlation analyses. Next, we conducted a series of stepwise regression analyses including covariates and all metacognitive variables to predict psychotic experiences (MUSEQ and PDI) across the four groups. SPSS 24 was used for all analyses and a $P$-value of $<.05$ was considered significant. Due to the novel nature of this research, a power analysis calculation was not possible using previously published data. Sample size was decided based on ability to recruit Tulpamancers and people who experience ASMR.

\section{Results}

\section{Demographics}

A total of 246 participants, recruited online, took part in the study. Three participants reported that they had been diagnosed with a psychotic disorder and, in accordance with the eligibility criteria, were removed from the analysis. Within the Tulpamancers group, 56\% $(N=45)$ reported experiencing ASMR. We split the Tulpamancers group into: Tulpamancer only and Tulpamancers reporting ASMR (Tulpamancer+), and we aimed to assess whether these two groups were different in terms of demographics. Age and gender did not differ between the two groups: gender $(p=.52)$ and age $(p$ $=.53)$ (see Table 1).

\section{Group comparisons}

Table 2 reports the descriptive statistics for unusual experiences and metacognition across the four groups. ANCOVA analyses, including age, gender, and ethnicity as covariates, demonstrated three between-group differences in metacognitive beliefs scale: 
Table 1. Descriptive and frequency statistics for demographics divided into four groups.

\begin{tabular}{|c|c|c|c|c|c|}
\hline & $\begin{array}{c}\text { Control }(N= \\
68)\end{array}$ & $\begin{array}{c}\operatorname{ASMR}(N= \\
99)\end{array}$ & $\begin{array}{l}\text { Tulpamancers }(N= \\
35)\end{array}$ & $\begin{array}{c}\text { Tulpamancer+ }(N \\
=44)\end{array}$ & Difference tests \\
\hline Age & $20.19(3.90)$ & $\begin{array}{c}30.53 \\
(10.94)\end{array}$ & $25.03(6.92)$ & $27.39(8.23)$ & $\begin{array}{c}\mathrm{F}(3,245)=20.59 \\
p<.001\end{array}$ \\
\hline $\begin{array}{l}\text { Gender (\% } \\
\text { female) }\end{array}$ & $87 \%$ & $23 \%$ & $40 \%$ & $27 \%$ & $\begin{array}{c}X^{2}(9,246)=52.9 \\
p<.001\end{array}$ \\
\hline \multicolumn{6}{|l|}{ Ethnicity } \\
\hline $\begin{array}{l}\text { Black or Black } \\
\text { British }\end{array}$ & $1.5 \%$ & $2 \%$ & $0 \%$ & $0 \%$ & $\begin{array}{c}X^{2}(12,246)=10.2 \\
p=.6^{\mathrm{a}}\end{array}$ \\
\hline White & $90 \%$ & $88 \%$ & $83 \%$ & $75 \%$ & \\
\hline $\begin{array}{l}\text { Asian or Asian } \\
\text { British }\end{array}$ & $1.5 \%$ & $1 \%$ & $8.5 \%$ & $2 \%$ & \\
\hline Mixed race & $4 \%$ & $5 \%$ & $0 \%$ & $11.5 \%$ & \\
\hline $\begin{array}{l}\text { Other ethnic } \\
\text { groups }\end{array}$ & $3 \%$ & $4 \%$ & $8.5 \%$ & $11.5 \%$ & \\
\hline Country of origin & & & & & $X^{2}(18,246)=124.05$ \\
\hline UK & 58 & 39 & 1 & 2 & $p<.001$ \\
\hline Europe & 6 & 11 & 11 & 5 & \\
\hline North America & 3 & 39 & 23 & 29 & \\
\hline South America & 0 & 3 & 0 & 4 & \\
\hline Australia & 0 & 3 & 0 & 2 & \\
\hline Asia & 1 & 2 & 0 & 2 & \\
\hline Africa & 0 & 2 & 0 & 0 & \\
\hline $\begin{array}{l}\text { Country of } \\
\text { residence }\end{array}$ & & & & & $\begin{array}{c}X^{2}(15,246)=138.19 \\
p<.001\end{array}$ \\
\hline UK & 63 & 44 & 1 & 1 & \\
\hline Europe & 3 & 10 & 11 & 6 & \\
\hline North America & 2 & 38 & 23 & 30 & \\
\hline South America & 0 & 2 & 0 & 4 & \\
\hline Australia & 0 & 4 & 0 & 2 & \\
\hline Asia & 0 & 1 & 0 & 1 & \\
\hline Africa & 0 & 0 & 0 & 0 & \\
\hline
\end{tabular}

Tukey posthoc: Age: control $<$ ASMR $^{* * *}$, control $<$ Tulpamancers*, control $<$ Tulpamancers $+^{* * *}$, ASMR $>$ Tulpamancers ${ }^{* *}$. NOTE: $x^{2}=$ chi-squared test, $\mathrm{F}=$ ANOVA, $p<.05={ }^{*}, p<.01{ }^{* * *}, p<.001^{* * *}$

Tulpamancer+ (identify as Tulpamancers and report ASMR).

${ }^{a}$ We converted ethnicity into White vs. Non-White to include as a covariate. $X^{2}(3,246)=5.49, p=.14$.

MCQ-30 total, $F(6,236)=3.27, p=.02, \eta^{2}=0.4$. Posthoc analyses with adjusted means show that Tulpamancers $(\mathrm{M}=60.49, \mathrm{SE}=2.36)$ scored significantly lower than the three other groups (control: $\mathrm{M}=67.32, \mathrm{SE}=1.8, p=.03, \mathrm{ASMR}: \mathrm{M}=68.81, \mathrm{SE}=1.43$, $p=.003$, and Tulpamancers+: $\mathrm{M}=68.54, \mathrm{SE}=2.15, p=.01)$. MCQ-30 positive beliefs about worry, $\mathrm{F}(6,238)=5.22, p=.002, \eta^{2}=0.06$. Posthoc analyses with adjusted means show that Tulpamancers $(\mathrm{M}=10.46, \mathrm{SE}=0.58)$ scored significantly lower than the three other groups (control: $\mathrm{M}=12.80, \mathrm{SE}=0.44, p=.002, \mathrm{ASMR}: \mathrm{M}=13.14, \mathrm{SE}=$ $0.35, p<.001$, and Tulpamancers+: $\mathrm{M}=12.36, \mathrm{SE}=0.52, p=.01)$. MCQ-30 negative beliefs about uncontrollability or danger of thoughts, $\mathrm{F}(6,238)=4.36, p=.005, \eta^{2}=$ 0.05 . Posthoc analyses with adjusted means show that Tulpamancers $(M=11.61, \mathrm{SE}=$ 0.54 ) scored significantly lower than two other groups (control: $M=13.19, S E=0.41$, $p=.03$, ASMR: $\mathrm{M}=13.92, \mathrm{SE}=0.33, p<.001)$, and Tulpamancers+ $(\mathrm{M}=13.17, \mathrm{SE}=$ $0.49, p=.03)$.

An ANCOVA analysis, including age gender, and ethnicity as covariates, demonstrated a between-group difference in MUSEQ total, $\mathrm{F}(6,235)=2.70, p=.047, \eta^{2}=0.03$, with Tulpamancers+ group reporting the highest score on the measure (see Table 2). Posthoc analyses with adjusted means show that Tulpamancers+ $(M=60.99$, $S E=$ 4.60) reported significantly higher unusual experiences than the three other groups 
Table 2. Descriptive statistics for continuous variables divided into four groups.

\begin{tabular}{|c|c|c|c|c|}
\hline & $\begin{array}{c}\text { Control }(N= \\
68)\end{array}$ & $\begin{array}{c}\operatorname{ASMR}(N= \\
99)\end{array}$ & $\begin{array}{l}\text { Tulpamancers }(N= \\
35)\end{array}$ & $\begin{array}{c}\text { Tulpamancer }+(N \\
=44)\end{array}$ \\
\hline MUSEQ total score & $45.16(27.6)$ & $48.48(27.11)$ & $46.91(30.27)$ & $63.14(31.52)$ \\
\hline MUSEQ auditory score & $11.90(5.48)$ & $12.36(6.05)$ & $10.66(6.31)$ & $13.43(7.0)$ \\
\hline MUSEQ visual score & $9.62(6.8)$ & $10.36(6.97)$ & $9.65(7.6)$ & $12.35(7.61)$ \\
\hline MUSEQ Olfactory score & $5.47(5.31)$ & $7.36(6.10)$ & $4.54(5.69)$ & $8.93(7.50)$ \\
\hline MUSEQ Gustatory score & $5.57(5.52)$ & $5.27(5.14)$ & $5.11(6.09)$ & $6.88(5.59)$ \\
\hline MUSEQ bodily sensed score & $9.57(7.0)$ & $10.13(7.04)$ & $11.66(8.50)$ & $15.34(7.86)$ \\
\hline MUSEQ Sensed Presence score & $3.03(2.89)$ & $2.85(2.82)$ & $5.46(3.92)$ & $5.39(3.84)$ \\
\hline PDI total score & $33.75(27.62)$ & $32.76(24.82)$ & $37.89(21.96)$ & $48.50(35.50)$ \\
\hline $\begin{array}{l}\text { PDI total score (square root } \\
\text { transformation) }\end{array}$ & $5.05(2.66)$ & $5.27(2.39)$ & $6.00(1.65)$ & $6.38(2.82)$ \\
\hline BCIS self-reflectiveness score & $16.22(3.89)$ & $15.0(4.11)$ & $14.11(3.59)$ & $15.73(3.34)$ \\
\hline BCSI self-certainty score & $7.81(2.53)$ & $8.42(2.57)$ & $6.86(3.39)$ & $8.48(2.77)$ \\
\hline $\mathrm{BCIS} \mathrm{Cl}$ score & $8.41(5.67)$ & $6.58(5.04)$ & $7.26(5.48)$ & $7.25(5.05)$ \\
\hline MCQ total score & $68.13(15.48)$ & $68.40(12.99)$ & $60.44(11.23)$ & $68.07(12.05)$ \\
\hline Cognitive confidence & $13.13(3.45)$ & $13.22(3.13)$ & $12.38(2.74)$ & $13.61(2.69)$ \\
\hline Positive beliefs of worry & $13.25(3.76)$ & $12.95(3.17)$ & $10.44(2.73)$ & $12.11(3.36)$ \\
\hline Cognitive self-consciousness & $12.96(2.86)$ & $13.41(2.84)$ & $12.74(2.80)$ & $14.36(2.65)$ \\
\hline $\begin{array}{l}\text { Negative beliefs about uncontrollability } \\
\text { and danger }\end{array}$ & $13.53(3.46)$ & $13.71(2.81)$ & $11.65(2.81)$ & $13.05(2.94)$ \\
\hline $\begin{array}{l}\text { Need to control thoughts } \\
\text { BCSS score }\end{array}$ & $15.26(3.77)$ & $15.15(3.28)$ & $13.24(3.15)$ & $14.79(3.47)$ \\
\hline BCSS negative self & $3.50(5.01)$ & $4.02(4.45)$ & $3.51(4.37)$ & $3.18(4.04)$ \\
\hline BCSS positive self & $10.34(5.84)$ & $10.27(6.38)$ & $11.83(5.53)$ & $11.52(5.81)$ \\
\hline BCSS negative other & $3.03(4.81)$ & $4.68(6.01)$ & $2.77(4.19)$ & $3.70(4.63)$ \\
\hline BCSS positive other & $11.37(5.77)$ & $9.28(6.49)$ & $8.66(4.32)$ & $8.59(6.0)$ \\
\hline
\end{tabular}

NOTE: $p<.05=^{*}, p<.01=^{* *}, p<.001^{* * *}$

Tulpamancer+ (identify as Tulpamancers and report ASMR)

(control: $\mathrm{M}=45.32, \mathrm{SE}=3.83, p=.01$, ASMR: $\mathrm{M}=49.92, \mathrm{SE}=3.086 p=.047$, and Tulpamancers: $\mathrm{M}=45.24 \mathrm{SE}=5.01, p=.02$ ).

ANCOVA analyses, including age, gender, and ethnicity as covariates, were also conducted for the following scales which were non-significant: MCQ-30 cognitive confidence, $\mathrm{F}(6,238)=1.02, \quad p=.39, \eta^{2}=0.01, \mathrm{MCQ}-30$ cognitive self-consciousness, $\mathrm{F}$ $(6,238)=2.30, p=.08, \eta^{2}=0.03$, MCQ-30 need to control thoughts, $\mathrm{F}(6,236)=2.29, p$ $=.08, \eta^{2}=0.03$, BCIS self-reflectiveness, $\mathrm{F}(6,239)=2.48, p=.06, \eta^{2}=0.03$, BCSS negative self, $\mathrm{F}(6,239)=1.16, p=.33, \eta^{2}=0.01$, BCSS positive self, $\mathrm{F}(6,239)=1.96, p=.12, \eta^{2}=0.02$, and PDI total $\mathrm{F}(6,239)=1.51, p=.21, \eta^{2}=0.02$.

\section{Correlational analyses}

Correlation matrices reporting relationships between metacognition (BCIS self-reflectiveness scale, MCQ-30, MCQ-30 subscales, BCSS negative self and positive self) and MUSEQ total and PDI total in the whole sample are provided in Table 3 and correlations in the four groups are provided in supplementary materials (Tables S1-4).

\section{Stepwise regression analyses}

Assumptions regarding multicollinearity, homoscedasticity, homogeneity of variance, and normality of random effects were met. There was a slight deviation from 
Table 3. Correlational matrix with metacognition (BCIS self-reflectiveness scale, MCQ-30, BCSS negative self and positive self) and MUSEQ total and PDI total in the full sample.

\begin{tabular}{|c|c|c|c|c|c|c|c|c|c|c|}
\hline & BCIS-SR & MCQ-30 total & MCQ-30 CC & MCQ-30 PBW & MCQ-30 CSC & MCQ-30 NBUD & MCQ-30 NCT & BCSS negative self & BCSS positive self & MUSEQ total \\
\hline MCQ-30 total & $\begin{array}{c}r=.5 \\
p<.001\end{array}$ & NA & & & & & & & & \\
\hline MCQ-30 CC & $\begin{array}{c}r=.33 \\
p<.001\end{array}$ & $\begin{array}{c}r=.82 \\
p<.001\end{array}$ & NA & & & & & & & \\
\hline MCQ-30 PBW & $\begin{array}{c}r=.42 \\
p<.001\end{array}$ & $\begin{array}{c}r=.86 \\
p<.001\end{array}$ & NA & NA & & & & & & \\
\hline MCQ-30 CSC & $\begin{array}{c}r=.39 \\
p<.001\end{array}$ & $\begin{array}{c}r=.80 \\
p<.001\end{array}$ & NA & NA & NA & & & & & \\
\hline MCQ-30 NBUD & $\begin{array}{c}r=.46 \\
p<.001\end{array}$ & $\begin{array}{c}r=.89 \\
p<.001\end{array}$ & NA & NA & NA & NA & & & & \\
\hline MCQ-30 NCT & $\begin{array}{c}r=.49 \\
p<.001\end{array}$ & $\begin{array}{c}r=.85 \\
p<.001\end{array}$ & NA & NA & NA & NA & NA & & & \\
\hline BCSS negative self & $\begin{array}{c}r=.24 \\
p<.001\end{array}$ & $\begin{array}{c}r=.32 \\
p<.001\end{array}$ & $\begin{array}{l}r=.18 \\
p=.004\end{array}$ & $\begin{array}{c}r=.27 \\
p<.001\end{array}$ & $\begin{array}{c}r=.26 \\
p<.001\end{array}$ & $\begin{array}{c}r=.31 \\
p<.001\end{array}$ & $\begin{array}{c}r=.32 \\
p<.001\end{array}$ & & & \\
\hline BCSS positive self & $\begin{array}{c}r=-.17 \\
p=.01\end{array}$ & $\begin{array}{c}r=-.3 \\
p<.001\end{array}$ & $\begin{array}{c}r=-.14 \\
p=.03\end{array}$ & $\begin{array}{l}r=-.33 \\
p<.001\end{array}$ & $\begin{array}{c}r=-.17 \\
p=.007\end{array}$ & $\begin{array}{c}r=-.3 \\
p<.001\end{array}$ & $\begin{array}{c}r=-.3 \\
p<.001\end{array}$ & $\begin{array}{l}r=-.55 \\
p<.001\end{array}$ & & \\
\hline MUSEQ total & $\begin{array}{c}r=.31 \\
p<.001\end{array}$ & $\begin{array}{c}r=.35 \\
p<.001\end{array}$ & $\begin{array}{c}r=.29 \\
p<.001\end{array}$ & $\begin{array}{c}r=.26 \\
p<.001\end{array}$ & $\begin{array}{c}r=.33 \\
p<.001\end{array}$ & $\begin{array}{c}r=.32 \\
p<.001\end{array}$ & $\begin{array}{c}r=.28 \\
p<.001\end{array}$ & $\begin{array}{c}r=.26 \\
p<.001\end{array}$ & $\begin{array}{c}r=-.18 \\
p=.01\end{array}$ & \\
\hline PDI total & $\begin{array}{c}r=.29 \\
p<.001\end{array}$ & $\begin{array}{c}r=.32 \\
p<.001\end{array}$ & $\begin{array}{c}r=.27 \\
p<.001\end{array}$ & $\begin{array}{c}r=.20 \\
p<.001\end{array}$ & $\begin{array}{c}r=.27 \\
p<.001\end{array}$ & $\begin{array}{c}r=.27 \\
p<.001\end{array}$ & $\begin{array}{c}r=.33 \\
p<.001\end{array}$ & $\begin{array}{c}r=.40 \\
p<.001\end{array}$ & $\begin{array}{c}r=-.12 \\
p=.06\end{array}$ & $\begin{array}{c}r=.55 \\
p<.001\end{array}$ \\
\hline
\end{tabular}

BCIS-SR = Beck Cognitive Insight Scale (self-reflectiveness subscale); MCQ-30= Metacognition Questionnaire 30; MCQ-30 CC = cognitive confidence; MCQ-30 PBW = positive beliefs about worry; MCQ-30 CSC = cognitive self-consciousness, MCQ-30 NBUD = negative beliefs about uncontrollability or danger; MCQ-30 NCT = need to control thoughts; BCSS = Brief Core Schema Scale; MUSEQ = Multimodal Unusual Sensory Experiences Questionnaire; PDI = Peters et al Delusion Inventory. All correlations were significant so bold signifies moderate-high correlations, when controlling for multiple comparisons $(p=.001)$. NA = intra-scale correlations were not conducted. 
homoscedasticity for MUSEQ and PDI regression analyses in the Tulpamancer group, but this was within reasonable limits.

\section{Control group}

MUSEQ. A stepwise regression assessed the predictive value of the MCQ-30 subscales, BCIS self-reflectiveness scale, and BCSS negative and positive self-schema scales on MUSEQ total for the control group. After including age, gender, and ethnicity as covariates, both BCIS-SR and MCQ-30 positive beliefs about worry were significant predictors ( $\mathrm{B}=0.42, p<.001 ; \mathrm{B}=0.31, p=.01$ ), and the full statistical model (including covariates) was significant, $R^{2}=.36, F(5,67)=6.85, p<.001$.

PDI. When controlling for covariates, MCQ-30 need to control thoughts and BCSS negative self-schema were a significant predictors $(\mathrm{B}=0.33, p=.01 ; \mathrm{B}=0.32, p=.01)$, and the full statistical model (including covariates) was significant, $R^{2}=.31, F(5,67)=$ $5.53, p<.001$.

\section{ASMR group}

MUSEQ. After including covariates, BCIS self-reflectiveness scale and MCQ-30 cognitive confidence were significant predictors $(\mathrm{B}=0.25, p=.02, \mathrm{~B}=0.25 p=.01)$ and the full statistical model (including covariates) was significant, $R^{2}=.23, F(5,96)=5.36, p<.001$.

$P D I$. After including covariates, BCSS negative self-schema and MCQ-30 cognitive confidence were significant predictor $(\mathrm{B}=0.41, p<.001 ; \mathrm{B}=0.23, p=.01)$ and the full statistical model (including covariates) was significant, $R^{2}=.29, F(5,97)=7.39, p<.001$.

\section{Tulpamancers only}

MUSEQ. After controlling for covariates, no metacognitive variable predicted MUSEQ in the Tulpamancer group. The statistical model including only covariates was non-significant, $R^{2}=.02, F(3,32)=0.16, p=.92$.

$P D I$. After including covariates, MCQ-30 cognitive self-consciousness was the only significant predictor $(\mathrm{B}=0.44, p=.02)$ and the full statistical model (including covariates) was non-significant, $R^{2}=.20, F(4,33)=1.83, p=.15$.

\section{Tulpamancer+ group}

MUSEQ total. When controlling for covariates, MCQ-30 need to control thoughts was the only significant predictor $(B=0.53, p<.001)$ and the full statistical model (including covariates) was significant, $R^{2}=.30, F(4,41)=3.99, p=.009$.

$P D I$. After including covariates, BCIS self-reflectiveness was the only significant predictor $(\mathrm{B}=0.61, p<.001)$ and the full statistical model was significant, $R^{2}=.34, F(4,42)$ $=4.83, p=.003$.

\section{Discussion}

This study compared self-reported metacognitive awareness, metacognitive beliefs, and self-schemas of three non-clinical populations, two of which have regular unusual sensory experiences. It was discovered that several Tulpamancers also experienced ASMR, and so four groups of individuals were compared; people who report experiencing ASMR, those who identify as Tulpamancers only, and those who identify as 
Tulpamancers and report ASMR (Tulpamancer+), as well as people who experience none of these phenomena. Together, these comparisons investigated the association between metacognition and non-clinical unusual sensory experiences.

\section{Unusual sensory experiences and hallucination-proneness}

Results partially supported our first hypothesis, as there was a between-group difference in hallucination-proneness, revealing that Tulpamancer+ have a higher proneness to hallucinations than the other three groups. Thus, individuals who have several different unusual sensory experiences appear to be more hallucination-prone. Across groups, there was also a strong positive correlation between hallucination-proneness and delusion-proneness, similar to previous evidence in non-clinical populations (Preti et al., 2007; Vellante et al., 2012).

\section{Unusual sensory experiences and delusion-proneness}

Results did not support our second hypothesis, as there were no group differences in delusion-proneness. Group mean scores were similar to previously reported, non-clinical samples (Peters et al., 2004). This indicates that, despite an association between hallucination-proneness and delusion-proneness across groups, these group differences are indeed focussed on unusual sensory experiences, rather than other unusual experiences such as delusional ideation.

\section{Unusual sensory experiences and metacognition}

Results partially support our third hypothesis. There were no between-group differences in self-reflection. Group mean scores were similar to previously reported community, non-clinical samples (Buchy et al., 2012). However, there was a group difference in endorsement of metacognitive beliefs, where the Tulpamancer group had endorsed fewer metacognitive beliefs (lower scores on the MCQ-30) relative to the other groups, as predicted. Generally, group mean scores were similar to community, non-clinical samples (Wells \& Cartwright-Hatton, 2004). This effect was driven by differences on positive beliefs about worry and negative beliefs about uncontrollability or danger of thoughts, where Tulpamancers scored lower on the MCQ-30. These differences may be explained by the meditative practices involved in Tulpamancy; research has demonstrated that mindfulness-related practices, and meditation-related thinking styles, are associated with fewer unhelpful metacognitive beliefs (Ottavi et al., 2019; Sugiura \& Sugiura, 2015). Further, meditation practice can improve objective metacognitive judgements in non-clinical samples (Baird et al., 2014). Results, therefore, indicate that people with these unusual sensory experiences have intact metacognitive self-reflection and similar levels of metacognitive belief endorsement and confidence in their beliefs to controls. Results support the suggestion that people with non-clinical unusual sensory experiences generally have intact metacognitive awareness and beliefs, compared to clinical groups. Further, there were no group differences in self-schemas, and mean scores for all sub-scales were equivalent to non-clinical samples reported (Fowler et al., 2006). 
However, direct comparisons between clinical groups and our groups of interest are needed.

A whole group correlation analysis indicated that there was a positive moderate association between metacognitive self-reflection and hallucination-proneness. This is the opposite of what we see in clinical groups who experience hallucinations (Beck et al., 2004; Kao et al., 2011) and similar to what has been observed in non-clinical studies about psychosis-spectrum experiences (Palmer-Cooper et al., 2020). However, there was a positive association between metacognitive beliefs and hallucination-proneness, similar to the relationship observed in clinical groups (Hill et al., 2012). Metacognitive self-reflection was moderately and positively correlated with metacognitive belief endorsement in a whole group analysis, and this was also the case for individual group correlations. Theories of metacognition and hallucination-proneness indicate that unusual sensory experiences are associated with metacognitive beliefs in both clinical and non-clinical groups, though evidence demonstrates this relationship is stronger in non-clinical samples (Varese \& Bentall, 2011). Together, this perhaps suggests metacognitive reflection on both thoughts and unusual sensory experiences is what differs between clinical and non-clinical groups, rather than beliefs or experiences themselves. When considering the difference in distress between clinical and non-clinical hallucination-prone individuals, more accurate reflection may allow for better perceived understanding of the experiences, and thus less distress. Further, ASMR and Tulpamancy are sought after, which indicates a degree of reflection and positive beliefs about these unusual sensory experiences.

\section{Metacognitive predictors}

In terms of predictors of unusual experiences, our fourth hypothesis was partially supported. Both self-reflection and metacognitive belief endorsement were significant predictors of hallucination-proneness in controls, whereby both higher self-reflection and higher cognitive self-consciousness, which is the tendency to focus attention on thought processes, positively predicted hallucination-proneness. Neither were predictive of delusion-proneness in controls. In people experiencing ASMR, less cognitive confidence in attention and memory was the only significant metacognitive predictor of hallucination-proneness. For delusion-proneness, less cognitive confidence and more negative self-schemas were significant predictors in this group. Neither measure of metacognition predicted hallucination-proneness in Tulpamancers, however cognitive selfconsciousness predicted delusion-proneness. For Tulpamancer+, metacognitive beliefs about the need to control thoughts were the only significant predictor of hallucination-proneness. Conversely, metacognitive self-reflection was the only significant predictor of delusion-proneness in this group.

Generally, the results demonstrate that metacognition can influence hallucinationproneness and delusion-proneness in the non-clinical population, regardless of the type of unusual sensory experiences they have, even if the experiences are sought after. Whilst there were some differences in the way in which metacognition predicted hallucination-proneness across these groups, results support previous research highlighting a relationship between metacognitive beliefs, awareness, and hallucination-proneness (Palmer-Cooper et al., 2020; Varese \& Bentall, 2011). Our results highlight that 
different unusual experiences may be influenced by or appraised using different cognitive mechanisms and metacognitive awareness. While speculation about whether this is cause or effect is outside the scope of the present study, these findings further highlight the complex nature of metacognitive processes and their role in understanding and maintaining unusual sensory experiences. Future work could also consider the role of wellbeing to build a more robust predictive model of these experiences and processes. The difference between the unusual sensory experiences investigated in the present study, and clinical experiences of hallucinations, seems to be in content and distress experienced. ASMR and Tulpamancy are both associated with increases in wellbeing (Isler, 2017; Poerio et al., 2018), whereas when hallucinations are experienced in clinical groups, they are typically associated with distress and reduced wellbeing. Future research is needed to identify mechanism of action in ASMR and Tulpamancy to understand differences in unusual sensory experiences between clinical and non-clinical groups and other groups who engage in absorbing activities and experiences with associated hallucination-like experiences, such as those who experience Game Transfer Phenomenon (Ortiz De Gortari \& Griffiths, 2015), would also be useful comparators. Finally, self-schemas appear to play a less consistent role across groups in relation to hallucination-proneness. This highlights that self-referential processing, rather than self-referential content, is important in understanding and maintaining unusual sensory experiences.

\section{ASMR and Tulpamancy}

This study reported that those who report experiencing only ASMR or Tulpamancy are not more prone to hallucinations or delusions than other non-clinical groups. However, Tulpamancers who also experience ASMR were more hallucination-prone than the other groups and this is likely due to these individuals experiencing more varied unusual sensations. Findings also indicate that, even when combined, these unusual sensory experiences do not automatically put an individual at risk of delusion-proneness. The difference between Tulpamancers and ASMR may be that Tulpamancers meditate and self-generate the experience (Mikles \& Laycock, 2015), whereas ASMR requires external input in the form of tactile, visual and auditory stimuli to occur (Barratt \& Davis, 2015; Roberts et al., 2021). To date, most ASMR research has focussed on people who initiate the experience using visual and auditory media. Further research should investigate the occurrence of ASMR in more naturalistic settings, i.e. people who experience ASMR in everyday life.

\section{Limitations}

This study relied on self-report of ASMR and Tulpamancy experiences. We acknowledge that this did not enable verification of experiences, and thus group status. Future research should ensure that more detailed screening is used to identify those with experience ASMR and Tulpamancy involves more in depth. For example, to screen those with ASMR Hostler et al. (2019) recommend 1) an in-depth description of ASMR be provided, 2) completion of an ASMR checklist, 3) presentation of ASMR videos and responding to questions about tingles, and 4) consistency tests, involving self-report of experiences at 
different time points. Similar approaches could be utilised to verify Tulpamancy experiences, such as 1) an in-depth description of Tulpamancy be provided and 2) space for individuals to write about their individual Tulpamancy experiences. To our knowledge, there are no validated screening questionnaires that allow for the quantitative comparison of Tulpamancer experiences.

Groups were not matched according to gender and age, due to the opportunity sampling recruitment strategy, which resulted in different age and gender profiles for each group. Age and gender were controlled in the analysis, but this was not a perfect resolution and future studies should aim to stratify the sample by important characteristics. Further, future studies should employ larger sample sizes to ensure acceptability for regression analyses.

\section{Conclusions}

Our study demonstrated that individuals who experienced more than one unusual sensory phenomenon, i.e. experience ASMR and Tulpamancy, were more hallucination-prone, but were not more prone to delusional thinking. Regarding metacognition, there were no clear differences between groups regarding metacognitive awareness, however, Tulpamancers had the lowest endorsement of metacognitive beliefs. Generally, metacognitive beliefs and self-reflection influence a person's hallucinatory experiences in the non-clinical population, even if the experiences are sought after. Results support the suggestion that metacognitive awareness is involved in the experience and processing of unusual sensory experiences, and suggest this may be the mechanism that reduces the distress associated with these experiences.

\section{Acknowledgements}

We would like to thank the participants of our public involvement discussions for shaping this study, and the participants who took part. We would also like to thank the Early Career Hallucination Research Group for their support and the opportunity to work on this project.

\section{Disclosure statement}

No potential conflict of interest was reported by the author(s ).

\section{Funding}

The author(s) reported there is no funding associated with the work featured in this article .

\section{Notes on contributors}

Emma Palmer-Cooper is a researcher and Lecturer at the Centre for Innovation in Mental Health, University of Southampton.

Nicola McGuire is a doctoral researcher at the Institute of Health and Wellbeing, University of Glasgow.

Abigail Wright is a researcher and Instructor at Massachusetts General Hospital and Harvard Medical School. 


\section{Data availability statement}

Data will be made available on the Open Science Framework https://osf.io/4j8gp/?view_only= 1f8e8c2ef0864eb9b746486577d14dbf

\section{ORCID}

Emma Palmer-Cooper (D) http://orcid.org/0000-0002-5416-1518

Nicola McGuire (D) http://orcid.org/b0000-0001-5332-7259

\section{References}

Addington, J., \& Tran, L. (2009). Using the brief core schema scales with individuals at clinical high risk of psychosis. Behavioural and Cognitive Psychotherapy, 37(2), 227-231. https://doi. org/10.1017/S1352465809005116

Austin, S. F., Mors, O., Nordentoft, M., Hjorthoj, C. R., Secher, R. G., Hesse, M., Hagen, R., Spada, M., Wells, A., Hjorthøj, C. R., Secher, R. G., Hesse, M., Hagen, R., Spada, M., Wells, A., Hjorthoj, C. R., Secher, R. G., Hesse, M., Hagen, R., ... Wells, A. (2015). Schizophrenia and metacognition: An investigation of course of illness and metacognitive beliefs within a first episode psychosis. Cognitive Therapy and Research, 39(1), 61-69. https://doi.org/10.1007/s10608-0149633-9

Baird, B., Mrazek, M. D., Phillips, D. T., \& Schooler, J. W. (2014). Domain-specific enhancement of metacognitive ability following meditation training. Journal of Experimental Psychology: General, 143(5), 1972-1979. https://doi.org/10.1037/a0036882

Balzan, R. P., Woodward, T. S., Delfabbro, P., \& Moritz, S. (2016). Overconfidence across the psychosis continuum: A calibration approach. Cognitive Neuropsychiatry, 21(6), 510-524. https:// doi.org/10.1080/13546805.2016.1240072

Barratt, E. L., \& Davis, N. J. (2015). Autonomous Sensory Meridian Response (ASMR): A flow-like mental state. PeerJ, 3, e851. https://doi.org/10.7717/peerj.851

Barratt, E. L., Spence, C., \& Davis, N. J. (2017). Sensory determinants of the autonomous sensory meridian response (ASMR): understanding the triggers. PeerJ, 5(10), e3846. https://doi.org/10. 7717/peerj.3846

Beck, A. T., Baruch, E., Balter, J. M., Steer, R. A., \& Warman, D. M. (2004). A new instrument for measuring insight: The Beck cognitive insight scale. Schizophrenia Research, 68(2-3), 319-329. https://doi.org/10.1016/s0920-9964(03)00189-0

Bright, M., Parker, S., French, P., Fowler, D., Gumley, A., Morrison, A. P., Birchwood, M., Jones, P. B., Stewart, S. L. K., \& Wells, A. (2018). Metacognitive beliefs as psychological predictors of social functioning: An investigation with young people at risk of psychosis. Psychiatry Research, 262, 520-526. https://doi.org/10.1016/j.psychres.2017.09.037

Buchy, L., Brodeur, M. B., \& Lepage, M. (2012). The beck cognitive insight scale: Psychometric properties in a Canadian community sample. Schizophrenia Research, 137(1-3), 254-255. https://doi.org/10.1016/j.schres.2012.02.020

Carse, T., \& Langdon, R. (2013). Delusion proneness in nonclinical individuals and cognitive insight The contributions of rumination and reflection. Journal of Nervous and Mental Disease, 201(8), 659-664. https://doi.org/10.1097/NMD.0b013e31829c4fe7

Corlett, P. R., Horga, G., Fletcher, P. C., Alderson-Day, B., Schmack, K., \& Powers, A. R. (2019). Hallucinations and strong priors. In Trends in cognitive sciences (Vol. 23, Issue 2, pp. 114-127). Elsevier Ltd. https://doi.org/10.1016/j.tics.2018.12.001

De Boer, J. N., Linszen, M. M. J., De Vries, J., Schutte, M. J. L., Begemann, M. J. H., Heringa, S. M., Bohlken, M. M., Hugdahl, K., Aleman, A., Wijnen, F. N. K., \& Sommer, I. E. C. (2019). Auditory hallucinations, top-down processing and language perception: A general population study. Psychological Medicine, 49(16), 2772-2780. https://doi.org/10.1017/S003329171800380X 
Ekinci, O., Albayrak, Y., \& Ekinci, A. (2012). Cognitive insight and Its relationship With Symptoms in deficit and nondeficit schizophrenia. Journal of Nervous and Mental Disease, 200(1), 44-50. https://doi.org/10.1097/NMD.0b013e31823e66af

Fonseca-Pedrero, E., Paino, M., Santarén-Rosell, M., Lemos-Giráldez, S., \& Muñiz, J. (2012). Psychometric properties of the Peters et al Delusions Inventory 21 in college students. Comprehensive Psychiatry, 53(6), 893-899. https://doi.org/10.1016/j.comppsych. 2012.01.007

Fowler, D., Freeman, D., Smith, B., Kuipers, E., Bebbington, P., Bashforth, H., Coker, S., Hodgekins, J., Gracie, A., Dunn, G., \& Garety, P. (2006). The Brief Core Schema scales (BCSS): psychometric properties and associations with paranoia and grandiosity in non-clinical and psychosis samples. Psychological Medicine, 36(6), 749-759. https://doi.org/10.1017/ S0033291706007355

Fowler, D., Hodgekins, J., Garety, P., Freeman, D., Kuipers, E., Dunn, G., Smith, B., \& Bebbington, P. E. (2012). Negative cognition, depressed mood, and paranoia: A longitudinal pathway analysis using structural equation modeling. Schizophrenia Bulletin, 38(5), 1063-1073. https://doi. org/10.1093/schbul/sbr019

Freeman, D., Pugh, K., Vorontsova, N., Antley, A., \& Slater, M. (2010). Testing the continuum of delusional beliefs: An experimental study using virtual reality. Journal of Abnormal Psychology, 119(1), 83-92. https://doi.org/10.1037/a0017514

Garety, P. A., \& Freeman, D. (1999). Cognitive approaches to delusions: A critical review of theories and evidence. British Journal of Clinical Psychology, 38(2), 113-154. https://doi.org/10. 1348/014466599162700

Gilleen, J., David, A., \& Greenwood, K. (2016). Self-reflection and set-shifting mediate awareness in cognitively preserved schizophrenia patients. Cognitive Neuropsychiatry, 21(3), 185-196. https://doi.org/10.1080/13546805.2016.1167031

Gracie, A., Freeman, D., Green, S., Garety, P. A., Kuipers, E., Hardy, A., Ray, K., Dunn, G., Bebbington, P., \& Fowler, D. (2007). The association between traumatic experience, paranoia and hallucinations: A test of the predictions of psychological models. Acta Psychiatrica Scandinavica, 116(4), 280-289. https://doi.org/10.1111/j.1600-0447.2007.01011.x

Hill, K., Varese, F., Jackson, M., \& Linden, D. E. J. (2012). The relationship between metacognitive beliefs, auditory hallucinations, and hallucination-related distress in clinical and non-clinical voice-hearers. British Journal of Clinical Psychology, 51(4), 434-447. https://doi.org/10.1111/j. 2044-8260.2012.02039.x

Hostler, T. J., Poerio, G. L., \& Blakey, E. (2019). Still more than a feeling: Commentary on cash et al., 'expectancy effects in the autonomous sensory meridian response' and recommendations for measurement in future ASMR research. Multisensory Research, 32(6), 521-531. https://doi. org/10.1163/22134808-20191366

Isler, J. (2017). Tulpas and mental health: A study of non-traumagenic plural experiences. Research in Psychology and Behavioral Sciences, 5(2), 36-44. https://doi.org/10.12691/rpbs-5-2-1

Jones, S. R., \& Fernyhough, C. (2006). The roles of thought suppression and metacognitive beliefs in proneness to auditory verbal hallucinations in a non-clinical sample. Personality and Individual Differences, 41(8), 1421-1432. https://doi.org/10.1016/j.paid.2006.06.003

Kao, Y.-C., Wang, T.-S., Lu, C.-W., \& Liu, Y.-P. (2011). Assessing cognitive insight in nonpsychiatric individuals and outpatients with schizophrenia in Taiwan: An investigation using the Beck Cognitive Insight scale. Bmc Psychiatry, 11, https://doi.org/10.1186/1471-244x-11-170

Kesting, M. L., \& Lincoln, T. M. (2013). The relevance of self-esteem and self-schemas to persecutory delusions: A systematic review. Comprehensive Psychiatry, 54(7), 766-789. https://doi.org/ 10.1016/j.comppsych.2013.03.002

Kimhy, D., Jobson-Ahmed, L., Ben-David, S., Ramadhar, L., Malaspina, D., \& Corcoran, C. M. (2014). Cognitive insight in individuals at clinical high risk for psychosis. Early Intervention in Psychiatry, 8(2), 130-137. https://doi.org/10.1111/eip.12023

Linscott, R. J., \& Van Os, J. (2013). An updated and conservative systematic review and meta-analysis of epidemiological evidence on psychotic experiences in children and adults: On the pathway from proneness to persistence to dimensional expression across mental 
disorders. Psychological Medicine, 43(6), 1133-1149). https://doi.org/10.1017/S0033291712 001626

Lysaker, P. H., Gagen, E., Wright, A., Vohs, J. L., Kukla, M., Yanos, P. T., \& Hasson-Ohayon, I. (2019). Metacognitive deficits predict impaired Insight in Schizophrenia across Symptom profiles: A latent class analysis. Schizophrenia Bulletin, 45(1), 48-56. https://doi.org/10.1093/ schbul/sby142

Lysaker, P. H., Vohs, J. L., Ballard, R., Fogley, R., Salvatore, G., Popolo, R., \& Dimaggio, G. (2013). Metacognition, self-reflection and recovery in schizophrenia. In Future neurology (Vol. 8, Issue 1, pp. 103-115). Future Medicine Ltd London. https://doi.org/10.2217/fnl.12.78

McErlean, A. B. J., \& Osborne-Ford, E. J. (2020). Increased absorption in autonomous sensory meridian response. PeerJ, 8(2), e8588. https://doi.org/10.7717/peerj.8588

Mikles, N. L., \& Laycock, J. P. (2015). Tracking the Tulpa : Exploring the 'Tibetan' origins of a contemporary paranormal idea. In Nova religio (Vol. 19, Issue 1, pp. 87-97). University of California Press. https://doi.org/10.1525/nr.2015.19.1.87

Mitchell, C. A. A., Maybery, M. T., Russell-Smith, S. N., Collerton, D., Gignac, G. E., \& Waters, F. (2017). The structure and measurement of unusual sensory experiences in different modalities: The multi-modality unusual sensory experiences questionnaire (MUSEQ). Frontiers in Psychology, 8, AUG. https://doi.org/10.3389/fpsyg.2017.01363

Morrison, A. P., Gumley, A. I., Ashcroft, K., Manousos, I. R., White, R., Gillan, K., Wells, A., \& Kingdon, D. (2011). Metacognition and persecutory delusions: Tests of a metacognitive model in a clinical population and comparisons with non-patients. British Journal of Clinical Psychology, 50(3), 223-233. https://doi.org/10.1348/014466510X511141

Ortiz De Gortari, A. B., \& Griffiths, M. D. (2015). Game Transfer phenomena and its associated factors: An exploratory empirical online survey study. Computers in Human Behavior, 51 (PA), 195-202. https://doi.org/10.1016/j.chb.2015.04.060

Ottavi, P., Passarella, T., Pasinetti, M., MacBeth, A., Velotti, P., Velotti, A., Bandiera, A., Popolo, R., Salvatore, G., \& Dimaggio, G. (2019). Metacognitive interpersonal mindfulness-based training for worry about Interpersonal events a pilot feasibility and acceptability study. Journal of Nervous and Mental Disease, 207(11), 944-950. https://doi.org/10.1097/NMD.0000000000001054

Palmer-Cooper, E., Searley, Z., \& Sapachlari, C. (2020). Schizotypal personality traits predict cognitive insight in a non-clinical population. Wessex Psychologist Bulletin, 17, 10-11.

Pechey, R., \& Halligan, P. (2012). Prevalence and correlates of anomalous experiences in a large non-clinical sample. Psychology and Psychotherapy: Theory, Research and Practice, 85(2), 150-162. https://doi.org/10.1111/j.2044-8341.2011.02024.x

Peters, E., Joseph, S., Day, S., \& Garety, P. (2004). Measuring delusional ideation: The 21-item Peters et al. Delusions Inventory (PDI). Schizophrenia Bulletin, 30(4), 1005-1022. https://doi. org/10.1093/oxfordjournals.schbul.a007116

Poerio, G. (2016). Could insomnia Be relieved with a YouTube video? The relaxation and calm of ASMR. In The restless compendium (pp. 119-128). Springer International Publishing. https:// doi.org/10.1007/978-3-319-45264-7_15

Poerio, G. L., Blakey, E., Hostler, T. J., \& Veltri, T. (2018). More than a feeling: Autonomous sensory meridian response (ASMR) is characterized by reliable changes in affect and physiology. PLOS ONE, 13(6), e0196645. https://doi.org/10.1371/journal.pone.0196645

Preti, A., Bonventre, E., Ledda, V., Petretto, D. R., \& Masala, C. (2007). Hallucinatory experiences, delusional thought proneness, and psychological distress in a nonclinical population. Journal of Nervous and Mental Disease, 195(6), 484-491. https://doi.org/10.1097/NMD.0b013e31802f205e

Reddit. (n.d.a). Reddit r/asmr. https://www.reddit.com/r/asmr/

Reddit. (n.d.b). Reddit r/Tulpas. https://www.reddit.com/r/Tulpas/

Roberts, N., Beath, A., \& Boag, S. (2021). Autonomous Sensory Meridian Response: Individual Differences and consciousness correlates. Psychology of Consciousness: Theory Research, and Practice, https://doi.org/10.1037/cns0000243

Scott, M., Rossell, S. L., Toh, W. L., \& Thomas, N. (2021). Understanding the role of self in auditory verbal hallucinations using a self-discrepancy paradigm. Psychology and Psychotherapy: Theory, Research and Practice, 268. https://doi.org/10.1111/papt.12276 
Smith, B., Fowler, D. G., Freeman, D., Bebbington, P., Bashforth, H., Garety, P., Dunn, G., \& Kuipers, E. (2006). Emotion and psychosis: Links between depression, self-esteem, negative schematic beliefs and delusions and hallucinations. Schizophrenia Research, 86(1-3), 181188. https://doi.org/10.1016/j.schres.2006.06.018

Sugiura, T., \& Sugiura, Y. (2015). Common factors of meditation, focusing, and cognitive behavioral therapy: Longitudinal relation of self-report Measures to worry, depressive, and obsessivecompulsive symptoms among nonclinical students. Mindfulness, 6(3), 610-623. https://doi.org/ 10.1007/s12671-014-0296-0

Thomas, N., Farhall, J., \& Shawyer, F. (2015). Beliefs about voices and schemas about self and others in psychosis. Behavioural and Cognitive Psychotherapy, 43(2), 209-223. https://doi.org/ 10.1017/S1352465813000817

Trauelsen, A. M., Gumley, A., Jansen, J. E., Pedersen, M. B., Nielsen, H. G. L., Trier, C. H., Haahr, U. H., \& Simonsen, E. (2016). Metacognition in first-episode psychosis and its association with positive and negative symptom profiles. Psychiatry Research, 238, 14-23. https://doi.org/10. 1016/j.psychres.2016.02.003

Varese, F., \& Bentall, R. P. (2011). The metacognitive beliefs account of hallucinatory experiences: A literature review and meta-analysis. Clinical Psychology Review, 31(5), 850-864. https://doi. org/10.1016/J.CPR.2010.12.001

Vellante, M., Larøi, F., Cella, M., Raballo, A., Petretto, D. R., \& Preti, A. (2012). Hallucination-like experiences in the nonclinical population. Journal of Nervous and Mental Disease, 200(4), 310315. https://doi.org/10.1097/NMD.0b013e31824cb2ba

Waters, F., \& Fernyhough, C. (2017). Hallucinations: A systematic review of points of similarity and difference across diagnostic classes. In Schizophrenia bulletin (Vol. 43, Issue 1, pp. 3243). Oxford University Press. https://doi.org/10.1093/schbul/sbw132

Wells, A. (2007). The attention Training technique: Theory, effects, and a metacognitive hypothesis on auditory hallucinations. In Cognitive and behavioral practice (Vol. 14, Issue 2, pp. 134138). Elsevier Inc. https://doi.org/10.1016/j.cbpra.2006.01.010

Wells, A., \& Cartwright-Hatton, S. (2004). A short form of the metacognitions questionnaire: Properties of the MCQ-30. Behaviour Research and Therapy, 42(4), 385-396. https://doi.org/ 10.1016/S0005-7967(03)00147-5

Wells, A., \& Matthews, G. (1994). Attention and emotion: A clinical perspective. Lawrence Erlbaum Associates. https://psycnet.apa.org/record/1995-97095-000

Wells, A., \& Matthews, G. (1996). Modelling cognition in emotional disorder: The S-REF model. Behaviour Research and Therapy, 34(11-12), 881-888. https://doi.org/10.1016/S0005-7967 (96)00050-2

Wright, A. C., Davies, G., Fowler, D., \& Greenwood, K. (2019). Three-year follow-up study exploring metacognition and function in individuals with first episode psychosis. Frontiers In Psychiatry, 10, https://doi.org/10.3389/fpsyt.2019.00182 